\title{
Secondary sulfate is internally mixed with sea spray aerosol and organic aerosol in the winter Arctic
}

\section{Rachel M. Kirpes et al.}

Correspondence to: Kerri A. Pratt (prattka@umich.edu) and Andrew P. Ault (aulta@umich.edu)

The copyright of individual parts of the supplement might differ from the CC BY 4.0 License. 


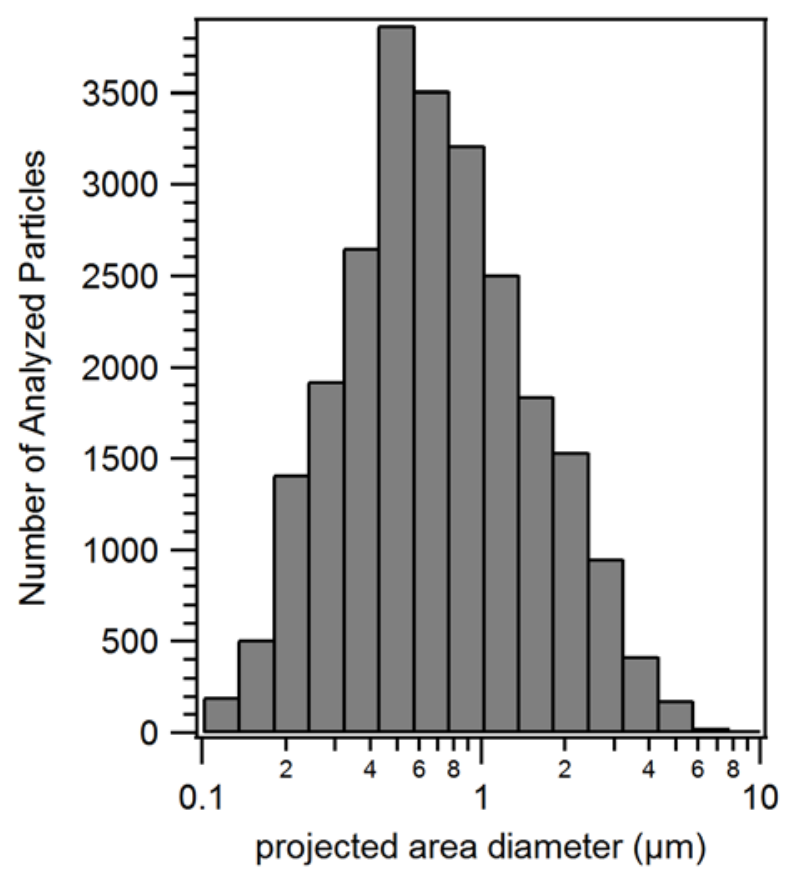

Figure S1: The number of individual particles analyzed by CCSEM-EDX for each of 16 log size bins. 

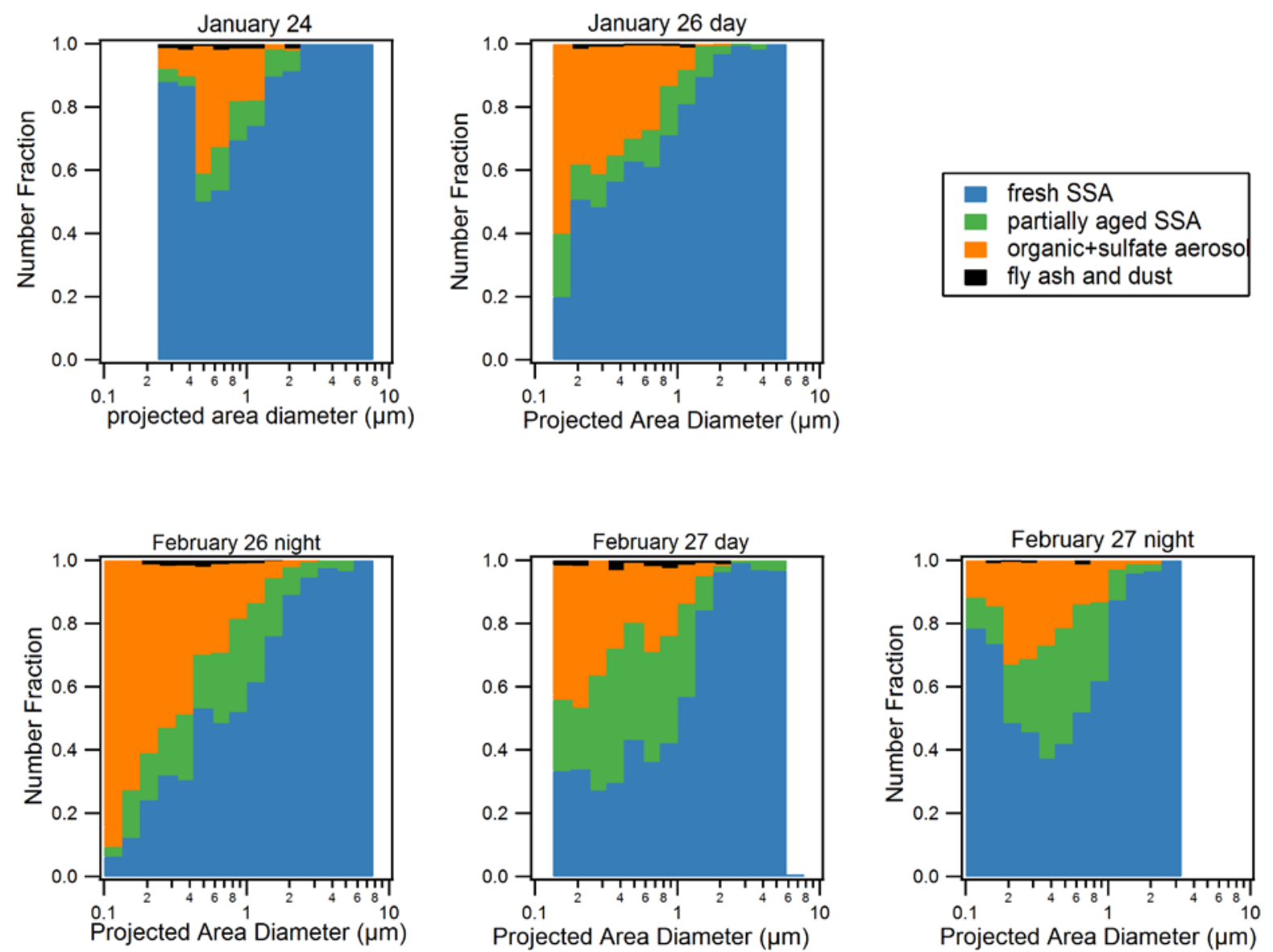

23 Figure S2: Size-resolved number fractions of particle types for additional sample periods not 24 shown in Figure 7. Particles were sorted into 16 log size bins. 